\title{
Study on multi-parameters of thermal infrared remote sensing anomalies of the Yushu earthquake
}

\author{
X. Lu ${ }^{1,2}$, Q. Y. Meng ${ }^{1}$, X. F. Gu ${ }^{1}$, X. D. Zhang ${ }^{3}$, P. Xiong ${ }^{3}$, W. Y. $\mathrm{Ma}^{2}$, and T. Xie ${ }^{2}$ \\ ${ }^{1}$ Institute of Remote Sensing and Digital Earth, China Academy of Sciences, Beijing, China \\ ${ }^{2}$ China Earthquake Networks Center, China Earthquake Administration, Beijing, China \\ ${ }^{3}$ Institute of Earthquake Science, China Earthquake Administration, Beijing, China \\ Received: 11 March 2014 - Accepted: 29 May 2014 - Published: 24 June 2014 \\ Correspondence to: Q. Y. Meng (mengqy@ radi.ac.cn) \\ Published by Copernicus Publications on behalf of the European Geosciences Union.
}

Study on

multi-parameters of thermal infrared remote sensing

anomalies

$X$. Lu et al.

\begin{tabular}{|c|c|}
\hline \multicolumn{2}{|c|}{ Title Page } \\
\hline Abstract & Introduction \\
\hline Conclusions & References \\
\hline Tables & Figures \\
\hline I4 \\
\hline \\
\hline Back \\
\hline Full Screen / Esc \\
\hline Printer-friendly Version \\
\hline Interactive Discussion \\
\hline
\end{tabular}




\section{Abstract}

Different temporal and special multi-parameters of infrared remote sensing anomalies of the Yushu earthquake, including the Outgoing Longwave Radiation (OLR), the Land Surface Temperature (LST) and surface temperature from the National Center for Envi5 ronmental Prediction (NCEP) were studied in this paper. All results confirmed previous observation of thermal anomalies in seismic region prior to this earthquake. Compared to the multi-parameter anomalies, the underground water temperature anomaly appeared first and lasted for the longest time; OLR anomalies reflected the radiation characteristics of the land surface medium as the first infrared parametric anomaly;

\section{Introduction}

Earthquake prediction is an international scientific problem. With social development, earthquake disasters seriously affect social economy. Thus, researching and monitoring of major natural disasters like earthquakes is a serious challenge for public security all over the world. The advantages of thermal anomaly observation with satellite remote sensing before earthquakes are macroscopic, objective, real-time and high density information compared with surface station observation, so it is often used in the observation of large range tectonic movement.

Thermal anomalies prior to earthquakes are a common natural phenomenon, and lies before earthquakes is a new exploration of earthquake prediction. More and more

NHESSD

2, 4439-4462, 2014

\section{Study on \\ multi-parameters of thermal infrared \\ remote sensing \\ anomalies \\ X. Lu et al.}

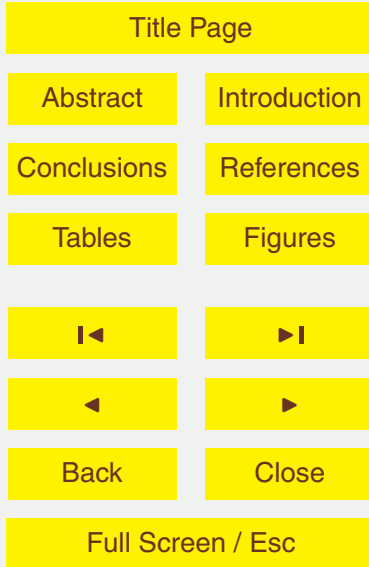

Printer-friendly Version

Interactive Discussion 
scientists have carried out this study. Zuji Qiang has carried out research (Qiang et al., 1991; Qiang and Du, 2001). Yaxin Bi (Bi et al., 2009) proposed to detect the seismic anomalies within data sequences of outgoing long wave radiation (OLR) with wavelet transformations as a data mining tool. They calculated the wavelet maxima curves that 5 propagate from coarser to finer scales in the defined grids over time and then identified strong singularities from the maxima lines distributing on the grids by only accounting for the characteristics of continuity in both time and space. Akhoondzadehan (2013) has proposed an Adaptive Network-based Fuzzy Inference System (ANFIS) to detect the thermal and Total Electron Content (TEC) anomalies of the Varzeghan, Iran, $10 \quad\left(M_{\mathrm{w}}=6.4\right)$ earthquake on 11 August $2012 \mathrm{NW}$ Iran. Valerio Tramutoli and colleagues have developed a robust satellite data analysis technique for environmental monitoring (Tramutoli, 1998) and space-time thermal anomalies on the Earth's surface recorded by satellites months to weeks before the occurrence of earthquakes (Tramutoli et al., 2001). He also found that areas dominated by diffusing gases which are heavier than 15 air (like $\mathrm{CO}_{2}$ ) show (as expected) anomalous TIR patterns which follow morphological lineaments (e.g. tectonic faults); in areas dominated by diffusing gases which are lighter than the air (like $\mathrm{CH}_{4}$ ) the TIR patterns observed spread over wide zones, following prevailing winds and diffusing around with less marked correlation with morphologic allineaments (Tramutoli et al., 2013). Ramesh P. Singh (Singh, 2010) used data from both the multi-satellite sensor and ground observation soon after the Wenchuan Earthquake on 12 May 2008 to research precursory signals. Tronin researched the thermal IR anomalies of satellite data in Japan and China (Tronin et al., 2002) and jointly analyzed the similarity between both satellite and ground observations related to earthquakes (Tronin et al., 2004). Ouzounov analyzed correlations between solid

25 Earth processes and atmosphere/ocean dynamics prior to strong earthquakes, selected examples from 2000 to 2001 and found evidence for such correlations, specifically for a thermal anomaly LST pattern that is apparently related to pre-seismic activity (Ouzounov and Freund, 2003). Finally satellite thermal IR phenomena associated with some of the major earthquakes in 1999-2003 were studied (Ouzounov et al., 2006).
NHESSD

2, 4439-4462, 2014

\section{Study on \\ multi-parameters of thermal infrared \\ remote sensing \\ anomalies}

X. Lu et al.

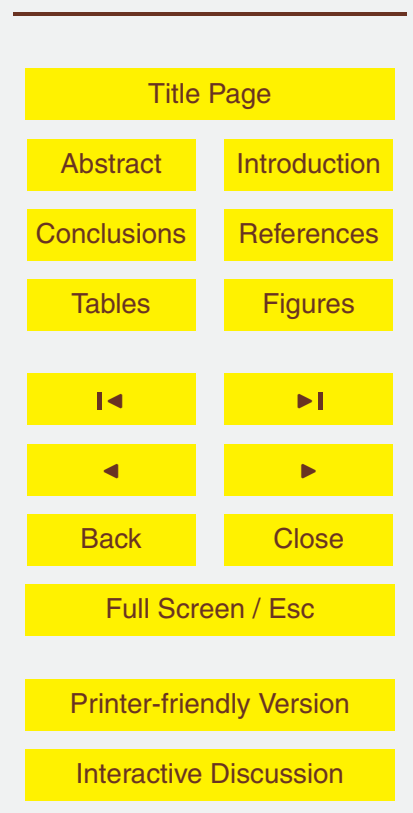


Before the destructive $M_{\mathrm{s}} 6.6$ Bam earthquake in Iran on 26 December 2003, a distinct anomaly in LST appeared (Saraf et al., 2008). Dey and R. P. Singh (Dey and Singh, 2003) analyzed surface latent heat flux (SLHF) from the epicentral regions of five recent earthquakes that occurred in close proximity to the oceans which were found to 5 show anomalous behavior.

The limitation of the geothermal anomaly for earthquake prediction came from the limitation of fixed observation networks, whether abnormal information was gained from meteorological stations or the well water temperature observation. Introducing space thermal infrared remote sensing technology into earthquake science is a new technical 10 means for precursory observation method of earthquake prediction, in particular the three-dimensional environment observation on the seismogenic zone (Lü et al., 1998). This paper used multi-source satellite remote sensing data to extract infrared multiparameter anomalies before earthquakes, researched the spatial and temporal characteristics of anomalies, and explored the relationship between thermal infrared anoma-

15 lies and earthquakes. Respectively, the LST (Land Surface Temperature) changes before and after the earthquake using China's environmental $\mathrm{HJ}-1 \mathrm{~B}$ satellite data, the OLR (Outgoing Long wave Radiation) changes before and after the earthquake using China's FY2-E satellite data, and temperature anomaly of NCEP (National Centers for Environmental Prediction) re-analysis global temperature data of this earthquake were calculated. These results show that the thermal anomalies could be an imminent precursor of strong earthquake.

\section{Brief introduction of the YuShu earthquake}

On 14 April 2010, $M_{\mathrm{s}} 7.1$ earthquake occurred in Yushu County of Qinghai Province in China, the epicenter $\left(33.2^{\circ} \mathrm{N}, 96.6^{\circ} \mathrm{E}\right)$ was located in the Ganzi-Yushu fault zone. The

fault was a large strike slip fault zone of the interior of the Qinghai Tibet plateau. It was also an important boundary fault of the Sichuan Yunnan rhombic block body (Zhou, 1997). The fracture was formed in the early West HOLLEY period, and moved strongly

\section{NHESSD}

2, 4439-4462, 2014

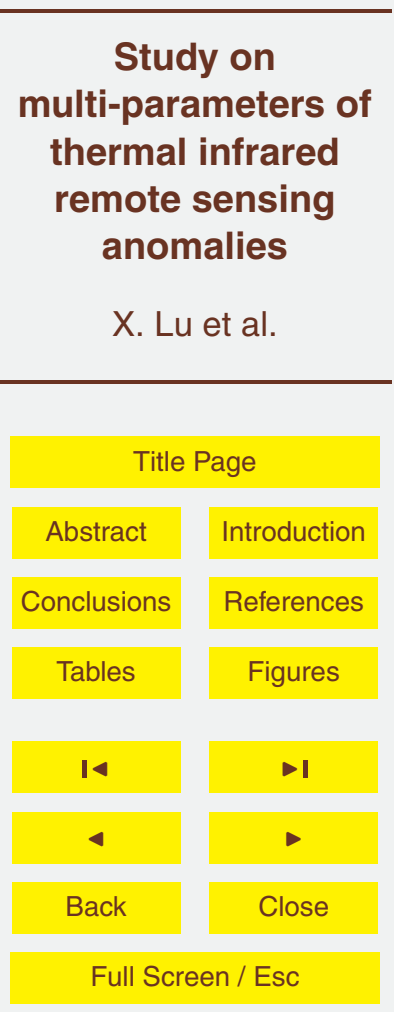

Printer-friendly Version Interactive Discussion 
during the Indo-Chinese epoch. Subsequently, thrust activities were the main activities of this fracture, and the fault has been a long-term active fault since the Quaternary period. The fracture was extending northwest for part of the Xianshuihe fault zone and the northern border of the Sichuan Yunnan rhombic block of Qinghai Tibet Plateau with 5 eastward extrusion. The structure of this fault was complex (Wen et al., 1985; Wang et al., 2008; Ren et al., 2010).

According to statistics, from 1 January 1990 to 31 December 2010, $M_{\mathrm{s}} \geq 5.0$ earthquakes in the study area occurred 36 times (Fig. 1). $M_{\mathrm{s}} 5.0-5.932$ times, $M_{\mathrm{s}} 6.0-6.93$ times, above $M_{\mathrm{s}} 7.0$ once (Table 1).

10 The M-T, frequency and time interval of earthquakes ( $\Delta \mathrm{T}-\mathrm{T}$ ) diagrams (Fig. 2) shows that there was group periodicity of $M_{\mathrm{s}} \geq 5.0$ magnitude earthquakes in the research area since 1990, and the quiet period between two earthquake groups was about three years. This study area came into the quiet period from the 7 May $2007 M_{\mathrm{s}} 5.6$ Tuo Ba County earthquake in Tibet, until the 14 April 2010 Qinghai Yushu earthquake 15 occurred.

\section{LST}

\subsection{Data}

Land surface temperature inversion is much more complex than the SST inversion, as land surface heterogeneity is much bigger than the ocean surface. Land surface temperature is relatively sensitive with vegetation types and soil moisture changes. On the surface of dense vegetation, land surface temperature inversed is the temperature of the vegetation canopy. For sparse surfaces, the surface temperature is a mixed average temperature of ground, vegetation canopy and other factors.

In September 2008, the A ("HJ-1A") and B ("HJ-1B") satellites were successfully 25 launched at China Taiyuan Satellite Launch Center. HJ-1A has two CCD sensors and a hyper spectral imager, and HJ-1B has two CCD sensors and an IRS sensor.
NHESSD

2, 4439-4462, 2014

\section{Study on \\ multi-parameters of thermal infrared \\ remote sensing \\ anomalies \\ X. Lu et al.}

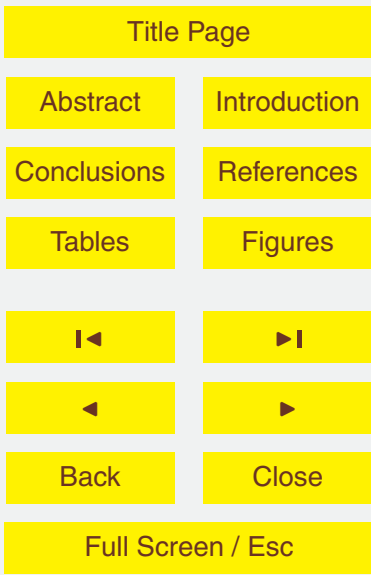

Printer-friendly Version Interactive Discussion 
The spatial resolution of $\mathrm{HJ}-1 \mathrm{~B}$ IRS in the near and middle infrared band $(\mathrm{B} 05,06$, 07 bands) is $150 \mathrm{~m}$, B08 thermal infrared band is $300 \mathrm{~m}$, width is $720 \mathrm{~km}$, and the revisiting period is 4 days ( $\mathrm{Li}, 2010)$.

We used two-grade products of $\mathrm{HJ}-1 \mathrm{~B}$ infrared data. In order to exclude the inter5 ference of sunshine and clouds, images were all clear images before dawn. There were 18 images from 2010 and 2009. First, the geometric correction, image scaling processing etc. were done, then the ARTIS algorithm was used to invert the surface temperature. Results were shown in Figs. 2 and 3.

\subsection{Method}

10 Artis (Artis et al., 1982) thought that the brightness temperature merely represents the blackbody temperature, while the most natural objects are not black, so we should use emissivity for the correction:

$T_{\mathrm{s}}=\frac{T}{1+(\lambda T / \rho) \ln \varepsilon}$

${ }_{15} \rho=h c / \sigma$

$T_{\mathrm{S}}$ is the land surface temperature, and its unit is $\mathrm{K} ; T$ is the brightness temperature of the sensor, and its unit is $\mathrm{K} ; \lambda$ is effective wave length, its value is $11.511 \mu \mathrm{m} ; \varepsilon$ is the surface emissivity, with reference to emissivity data of ZhiHao Qin single window algorithm; $h$ is the Planck constant, and the value is $6.626 \times 10^{-34} \mathrm{~J} \mathrm{~s}$; $c$ is the speed of light and its value is $2.998 \times 10^{8} \mathrm{~m} \mathrm{~s}^{-1} ; \sigma$ is Boltzmann constant and its value is $1.38 \times 10^{-23} \mathrm{~J} \mathrm{~K}^{-1}$.

\subsection{Results}

We selected images from March to May to calculate LST. In early March, for LST, no abnormal phenomena appeared in the study area, but in 14 March 2010 a month before the Yushu earthquake, an obvious scaly cloud appeared in the study area, right through
NHESSD

2, 4439-4462, 2014

\section{Study on \\ multi-parameters of \\ thermal infrared \\ remote sensing \\ anomalies \\ $X$. Lu et al.}

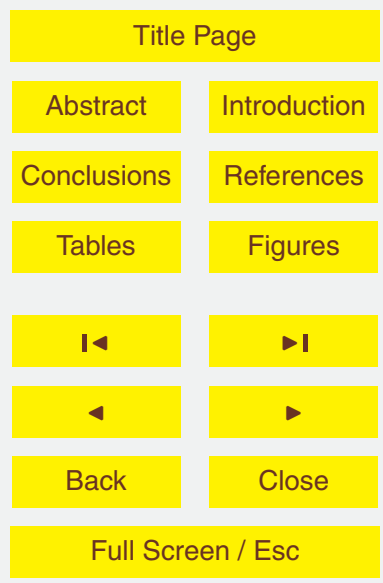

Printer-friendly Version

Interactive Discussion 
the Yushu earthquake epicenter. A high-value LST anomaly appeared in the southwest region adjacent to the epicenter in 10 April 2010 along the fault zone in Fig. 3. Due to satellite observation cycles and the weather, the changes of anomaly a few days later could not be observed. The anomaly gradually expanded to the epicenter and 5 dissipated in the subsequent images. On 18 April, the abnormal region covered the epicenter, and higher value anomaly zones were still located in the southwest region of epicenter and along the fault zone, showing the correlation between the fault structure and surface temperature anomaly. Geothermal values of abnormal area on 26 April were significantly lower than the values on 18 April and gradually dissipated, and LST of this region returned to a normal state in late May. Figure 3 shows the appearancediffusion and concentration-decay-disappear process of LST abnormal before and after the earthquake as a better pre-earthquake abnormal.

In order to reduce the influence of possible interference factors for extracting seismic information, such as weather, vegetation and topography, this paper also calculated 15 LST results of the same period in $\mathbf{2 0 0 9}$ of the research area as background information. Then we discussed the different spatial-temporal features of LST. LST of Fig. 3 shows there was no significant high value anomaly in the three months from March to May in 2009, and the temperature was always maintained in the normal state. This result further confirmed the reliability of the LST imminent earthquake anomalies of the 14 April 2010 Qinghai Yushu earthquake.

\section{OLR (Outgoing Longwave Radiation)}

\subsection{Data}

FY-2E static meteorological satellite was launched in December 2008 and its orbit is fixed at $105^{\circ} \mathrm{E}$ above the Equator. The entire covered area is $50^{\circ} \mathrm{N}-50^{\circ} \mathrm{S}$ and $55-$

\section{NHESSD}

2, 4439-4462, 2014

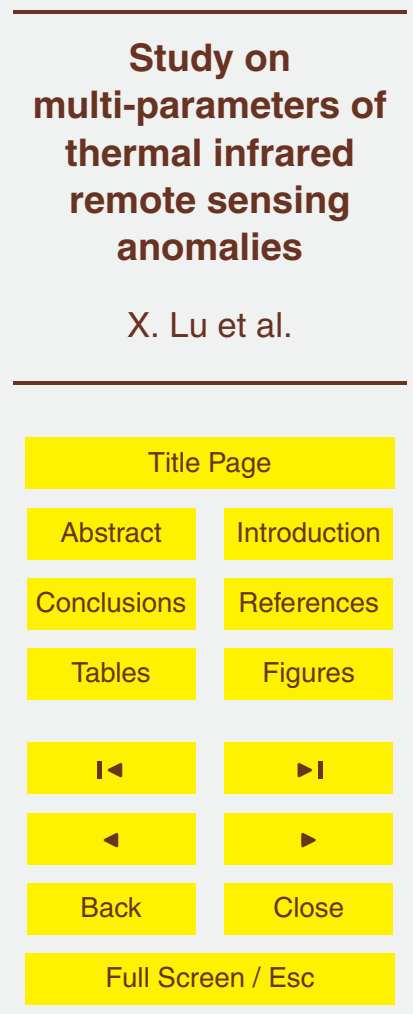

Printer-friendly Version Interactive Discussion 
December 2009, and its observation was taken every three hours. The resolution of infrared OLR data is $5 \mathrm{~km}$.

We chose the long wave radiation data in the space range of $94-100^{\circ} \mathrm{E}, 30-36^{\circ} \mathrm{N}$ centered on the quake's epicenter for analysis. The solar radiation in the daytime will 5 influence the surface OLR data, so in order to avoid the influence of solar radiation; we selected the data from 22:00-06:00 LT (Local Time) for our analysis. In order to extract information from more frequencies and to analyze anomalies against normality through comparison, the length of daily brightness temperature series was two years. We extracted a trend component whose period was about one year and more in bright10 ness temperature of every pixel by using a low-pass filter and used a 1.5 times mean variance threshold to simply eliminate effects of clouds. If the brightness temperature of one pixel was lower than the threshold, it was regarded as cloud-top temperature and was substituted with the temperature of its trend component of the same date (Xie et al., 2013).

\subsection{Method}

Wavelet transform is an effective method for analyzing non-stationary signal. It is widely used for studies in geophysics, seismic prospecting and other research fields (Kumar and Foufoula, 1997; Xie et al., 2013).

The wavelet transform with limited time series was defined as:

$W_{\psi} f(a, b)=\int_{-\infty}^{\infty} f(t) \psi_{a, b}^{*}(t) \mathrm{d} t$

Where the asterisk denotes the complex conjugate; $a$ and $b$ denote the wavelet scale and the localized time index. $\psi_{a, b}(t)=\frac{1}{\sqrt{a}} \psi_{a, b}\left(\frac{t-b}{a}\right)$ denotes the mother function.

Here, we chose Morlet wavelet in our analysis:

NHESSD

2, 4439-4462, 2014

\section{Study on \\ multi-parameters of thermal infrared \\ remote sensing \\ anomalies \\ X. Lu et al.}

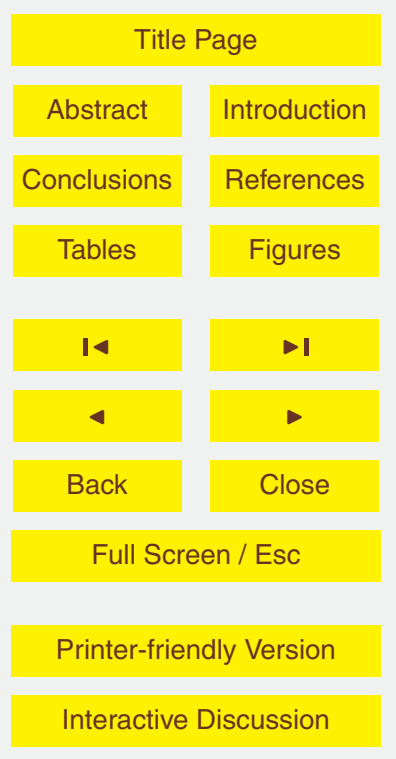

${ }_{25} \psi(\omega)=\pi^{-1 / 4} e^{-\left(\omega-\omega_{0}\right)^{2} / 2}$ 
where $\omega_{0}$ is the nondimensional frequency. If $\omega_{0} \geq 5$, Morlet wavelet satisfies the admissibility condition, and $\omega_{0}$ is taken to be 6 here.

Spatial-temporal analysis of mass data cannot be done easily, so we used a common mathematical method of waveform data processing, namely, power spectrum method.

5 The power spectrum method can obtain the dominant frequency and amplitude. We can research the similarities and differences between the power spectrum near earthquake times and other times. Wavelet power spectrum can be defined as $\left|W_{\psi} f(a, b)\right|^{2}$, then, we calculated the relative spectrum change of different band:

$R_{\psi}(a, b)=\left|W_{\psi} f(a, b)\right|^{2} / \bar{W}^{2}(a, b)$

Where

$\bar{W}^{2}(a, b)=\frac{1}{N} \sum_{l=0}^{N-1}\left|W_{l} f(a, b)\right|^{2}$

$\bar{W}^{2}(a, b)$ is the global wavelet spectrum. Therefore, $R_{\psi}(a, b)$ denotes the RWPS (Relative Wavelet Power Spectrum) which is the ratio of time spectrum and the mean of two-year spectrum and $N$ is the length of time series.

\subsection{Results}

A sporadic small range thermal infrared anomaly began to appear in the study area around the epicenter in early March, then the abnormal region gradually expanded to

the epicenter area. The anomaly's relative spectral amplitude increased, and anomalies were mainly concentrated in the southern region of the epicenter. Anomaly amplitude and area reached a maximum of about 11 on 26 March, which meant that the power was 11 times its average of two years. After that, the anomaly region decreased gradually, and anomaly had almost completely disappeared until the 14 April Yushu
NHESSD

2, 4439-4462, 2014

\section{Study on \\ multi-parameters of thermal infrared \\ remote sensing \\ anomalies \\ X. Lu et al.}

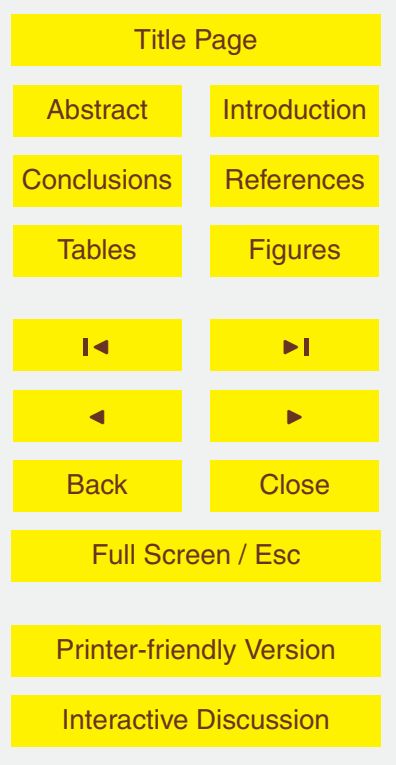




\section{NCEP}

Infrared waves cannot penetrate clouds, when there are lots of clouds over the epicenter region, the infrared thermal of temperature is not recorded correctly (Ma et al., 2012). In order to reduce the influence of interference factors, the NCEP reanalysis

5 global temperature data (containing Surface Marine Data, Surface Land Synoptic etc.) was used in the study, and all the observed data could more comprehensively and accurately reflect the actual temperature conditions under action of multiple factors by assimilating this data. Twelve days of data from 4 to 15 April was calculated by the difference calculation method, which was the value minus the average value of the same days in the past ten years. The result is shown in Fig. 6.

The results showed that NCEP anomalies of the Yushu earthquake were obvious, and there were no increasing temperature anomalies in the period from 4 to 11 April in study area. However, the suddenly warming of the southwest area of the epicenter on 12 April had a large abnormal area. Anomalies reduced and appeared to be moving to epicenter area in 13 April, then earthquake happened on 14 April. There was no abnormal phenomenon during 14 and 15 April, which was different to the traditional process that thermal anomalies appear-strengthen-peak-damping-earthquake-silent before earthquake. Only the abnormal temperature rapid increased and transferred until attenuation on 12 and 13 April.

\section{Water temperature of Yushu well}

Yushu well is located in the Tuanjie Village of Yushu County in Qinghai Province, with coordinates $97.02^{\circ} \mathrm{E}, 33.01^{\circ} \mathrm{N}$. The distance from the well to the Wenchuan earthquake epicenter was $643 \mathrm{~km}$, and only $46 \mathrm{~km}$ to the Yushu earthquake epicenter. The depth of the geothermal observation well was $105 \mathrm{~m}$, and the SZW-1A digital thermometer used as the water temperature observation instrument was placed in $100 \mathrm{~m}$ depth mainly composed of Mesozoic Jurassic granite. The well was filled with water, so

NHESSD

2, 4439-4462, 2014

Study on

multi-parameters of thermal infrared

remote sensing

anomalies

X. Lu et al.

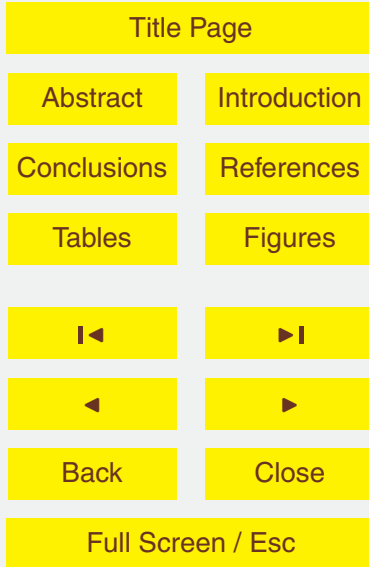

Printer-friendly Version

Interactive Discussion 
the observation data was water temperature. Because of instrument failure, incomplete data of 2009 from Fig. 7 can be seen. Water temperature of Yushu well had a rising trend as the normal background for many years. During the period from 1 January 2008 to 14 April 2010 Yushu earthquake, there were seven earthquakes with mag5 nitude above $M_{\mathrm{s}} 5.0$ occurring within $650 \mathrm{~km}$ radius of the well, and three cases had a better correspondence with the well water temperature anomalies. Respectively were the 12 May 2008 Wenchuan $M_{\mathrm{s}} 8.0$ earthquake, Qinghai Delingha $M_{\mathrm{s}} 5.0$ earthquake on 21 December 2009 and the 14 April 2010 Qinghai Yushu earthquake of $M_{\mathrm{s}} 7.1(\mathrm{He}$ et al., 2012). Sudden step change phenomenon of Yushu well water temperature oc10 curred about 60 days before the 12 May $2008 M_{\mathrm{s}} 8.0$ Wenchuan earthquake, and the Wenchuan earthquake occurred in the numerical recovery process. In addition, the step change anomaly period before the Delingha $M_{\mathrm{s}} 5.0$ earthquake was less than two months and before the Yushu $M_{\mathrm{s}} 7.1$ earthquake was about 90 days from Fig. 7 .

\section{Conclusions}

15 This paper researched different temporal-spatial infrared anomalies of the Yushu earthquake used by a variety of satellite infrared data and all results showed there were infrared abnormal phenomena in seismic region. The LST of satellite $\mathrm{HJ}$-1B showed abnormal areas mainly concentrated in the southwest of the epicenter which started on 10 April and lasted for 16 days; the OLR abnormal phenomenon of FY-2E satellite began on 15 March and lasted for 17 days, and the abnormal area was located in the south of the epicenter. The brightness temperature anomaly of FY-2E (Xie et al., 2013) began on 29 March and lasted for 17 days, with an abnormal area also located in the south of the epicenter. The NCEP anomaly appeared later, strong anomalies of high temperature suddenly appearing on 12 April in the southwest area of the epicenter, but the anomaly lasted only for two days. Compared with the multi-parameter anomalies, the abnormal variation of underground water temperature appeared first and lasted for the longest time; OLR infrared anomalies were first. Because OLR was
NHESSD

2, 4439-4462, 2014

\section{Study on \\ multi-parameters of thermal infrared \\ remote sensing \\ anomalies \\ X. Lu et al.}

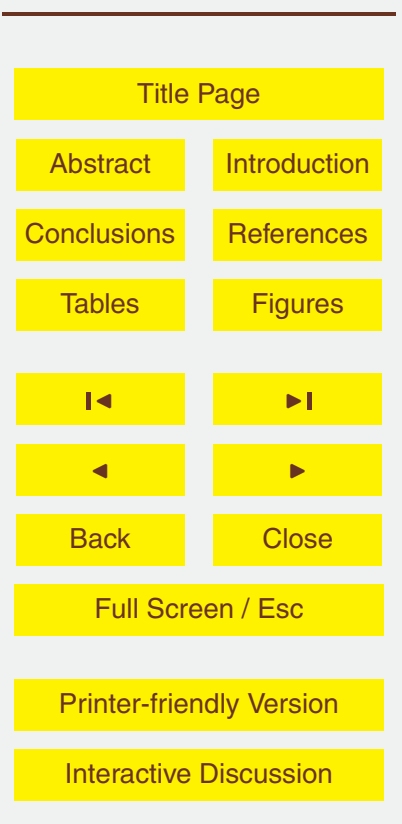


the long wave electromagnetic energy directly radiated outward from the earth itself, it mainly reflected the radiation characteristics of the surface medium and was the most direct source of anomalies. Thus, OLR was first observed phenomenon by radiation calculation; brightness temperature, the converted result by calculating the radiation 5 value of underlying surface, and reflected the atmospheric radiation characteristics of the land surface and atmosphere above it. Thus it would appear slightly later than OLR abnormal; while the LST inverted the cloud top temperature, and the temperature of clouds could rise when thermal radiation reached the cloud height, so, this may be the reason why LST abnormalities appeared later than OLR; NCEP temperature reflected 10 the average atmosphere temperature with a certain vertical thickness, and it was the bulk mixed atmosphere temperature through the atmospheric radiation, convection and turbulent exchange, so it was the latest abnormality. The sequence of observed anomalous characteristics of each parameter and possible intrinsic physical properties can be explained by the time series of above anomalies. The anomaly duration of OLR, TBB and LST were most similar. What's more, the anomalies before earthquake of different observation means were all located in the south or southwest of the epicenter, and they were consistent with the faults distribution of this region.

Acknowledgements. The authors would like to acknowledge Satellite Meteorological Center, China Meteorological Administration and Satellite Environment Center, Ministry of Environmental Protection, for the data service. We thank anonymous reviewers. This work is supported by the project of "Study on Seismic Anomalous Features of the Qinghai Tibet Plateau based on the Multi-parameters of Infrared Remote Sensing" (Grant No.: Y3YI2702KB) and the project of "Earthquake tracking of the China Earthquake Administration" (Grant No.: 405141526).

\section{References}

Akhoondzadeh, M.: An adaptive network-based Fuzzy inference system for the detection of thermal and TEC anomalies around the time of the Varzeghan, Iran, $\left(M_{\mathrm{w}}=6.4\right)$ earthquake of 11 August 2012, Adv. Space Res., 52, 837-852, 2013.

\section{NHESSD}

2, 4439-4462, 2014

\section{Study on \\ multi-parameters of thermal infrared \\ remote sensing \\ anomalies}

X. Lu et al.

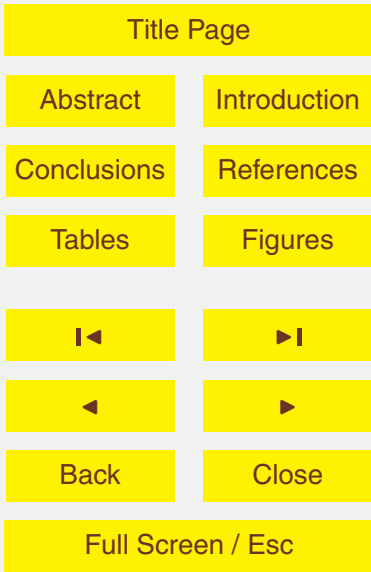

Printer-friendly Version

Interactive Discussion 
Bi, Y. X., Wu, S. L., Xiong, P., and Shen, X. H.: A Comparative Analysis for Detecting Seismic Anomalies in Data Sequences of Outgoing Longwave Radiation, Knowledge Science, Eng. Manage., 285-296, doi:10.1007/978-3-642-10488-6_29, 2009.

Dey, S. and Singh, R. P.: Surface latent heat flux as an earthquake precursor, Nat. Hazards Earth Syst. Sci., 3, 749-755, doi:10.5194/nhess-3-749-2003, 2003.

Gorny, V. I., Salman, A. G., Tronin, A. A., and Shilin, B. V.: The earth's outgoing IR radiation as an indicator of seismic activity, Proc. Acad. Sci. USSR, 301, 67-69, 1988.

Guo, X., Zhang, Y. S., Wei, C. X., Zhong, M. J., and Zhang, X.: OLR anomalies for the Lushan $M_{\mathrm{s}} 7.0$ earthquake, Acta Seismologica Sinica, 35, 731-737, 2013.

$10 \mathrm{He}$, A. H., Zhao, G., Liu, C. L., and Fan, L. L.: The anomaly characteristics before Wenchuan earthquake and Yushu earthquake in QinghaiYushu and Delingha geothermal observation wells, Chinese J. Geophys., 55, 1261-1268, doi:10.6038/j.issn.0001-5733.2012.04.021, 2012 (in Chinese).

Kumar, P. and Foufoula, E.: Wavelet analysis for geophysical applications, Rev. Geophys., 35, $15 \quad 385-412,1997$.

Li, J. G.: HJ-1B IRS Thermal Infrared Band In-flight Radiometric Calibration and Application, Ph.D. thesis, Institute of Remote Sensing Applications, Chinese Academ of Sciences. China, 132 pp., 2010.

Lü, Q. Q., Ding, J. H., and Cui, C. Y.: Satellite thermal infrared anomaly before the Zhangbei earthquake $M_{\mathrm{s}}=6.2$, Earthquake, 18, 240-244, 1998.

Ma, W. Y., Liu, C. B., and Saumitra, M.: A study on abnormal temperature variation of the earthquake in Jiujiang, China (2005) according to additive tectonics stress, High Technol. Lett., 18, 214-218, doi:10.3772/j.issn.1006-6748.2012.02.019, 2012.

Ouzounov, D. and Freund, F.: Mid-infrared emission prior to strong earthquakes analyzed by remote sensing data, Adv. Space Res., 33, 268-273, 2003.

Ouzounov, D., Bryant, N., Logan, T., Pulinets, S., and Taylor, P.: Satellite thermal IR phenomenaassociated with some of the major earthquakes in 1999-2003, Phys. Chem. Earth, 31, 154-163, 2006.

Qiang, Z. J. and Du, L. T.: Earth degassing, forest fire and seismic activities, Earth Science Frontiers, 8, 235-245, 2001.

Qiang, Z. J., Xu, X. D., and Dian, C. G.: Thermal infrared anomaly precursors of impending earthquakes, Chin. Sci. Bull, 35, 1324-1327, 1990.

\section{NHESSD}

2, 4439-4462, 2014

\section{Study on \\ multi-parameters of \\ thermal infrared \\ remote sensing \\ anomalies}

X. Lu et al.

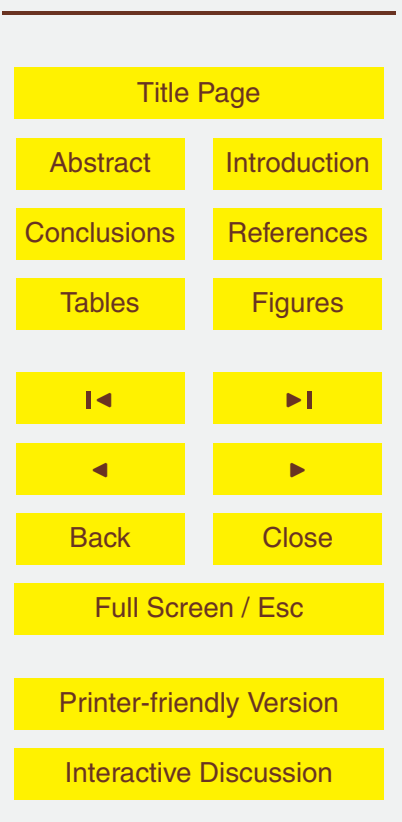


Ren, J. J., Xie, F. R., Liu, D. Y., and Zhang, A. W.: Study of tectonics, seismicity and recurrence interval of Yushu 2010 Earthquake, Qinghai Province, Technology for Earthquake Disaster Prevention, 5, 228-233, 2010.

Saraf, A. K., Rawat, V., Banerjee, P., Choudhury, S., Panda, S. K., Dasgupta, S., and Das, J. D.: $5 \quad$ Satellitedetection of earthquake thermal precursors in Iran, Nat. Hazard, 47, 119-135, 2008.

Singh, R. P.: Satellite observations of the Wenchuan Earthquake, 12 May 2008, Int. J. Remote Sens., 31, 3335-3339, doi:10.1080/01431161003727820, 2010.

Tramutoli, V.: Robust AVHRR Techniques (RAT) for environmental monitoring: theory and applications, in: Earth Surface Remote Sensing II, edited by: Cecchi, G. and Zilioli, E., SPIE, $10 \quad$ Barcelona, Spain, 101-113, 1998.

Tramutoli, V., Bello, G. D., Pergola, N., and Piscitelli, S.: Robust satellite techniques for remote sensing of seismically active areas, Ann. Geofis., 44, 295-312, 2001.

Tramutoli, V., Cuomo, V., Filizzola, C., Pergola, N., and Pietrapertosa, C.: Assessing the potential of thermal infrared satellite surveys for monitoring seismically active areas, The case of Kocaeli (Ýzmit) earthquake, 17 August 1999, Remote Sens. Environ., 96, 409-426, 2005.

Tramutoli, V., Aliano, C., Corrado, R., Filizzola, C., Genzano, N., Lisi, M., Martinelli, G., and Pergola, N.: On the possible origin of thermal infrared radiation (TIR) anomalies in earthquakeprone areas observed using robust satellite techniques (RST), Chem. Geol., 339, 157-168, 2013.

20

Tronin, A. A.: Satellite thermal survey - a new tool for the studies of seismoactive regions, Int. J. Remote Sens., 17, 1439-1455, 1996.

Tronin, A. A., Hayakawa, M., and Molchanov, O. A.: Thermal IR satellite data application for earthquake research in Japan and China, J. Geodyn., 33, 519-534, 2002.

Tronin, A. A., Biagi, P. F., Molchanov, O. A., Khatkevich, Y. M., and Gordeeev, E. I.: Temperature variations related to earthquakes from simultaneous observation at the ground stations and by satellites in Kamchatka area, Phys. Chem. Earth, 29, 501-506, 2004.

Wang, S., Fan, C., Wang, G., and Wang, E.: Late Cenozoic deform action along the northwestern continuation of the Xianshuihe fault system, Eastern Tibetan Plateau, Geol. Soc. Am. Bull., 120, 312-327, 2008.

so Wen, X. Z., Huang, S. M., and Jiang, Z. X.: Neotectonic features of the Ganzi-Yushu fault zone and assessment of its earthquake risk, Seismology and Geology, 7, 23-32, 1985.

\section{NHESSD}

2, 4439-4462, 2014

\section{Study on \\ multi-parameters of \\ thermal infrared \\ remote sensing \\ anomalies}

X. Lu et al.

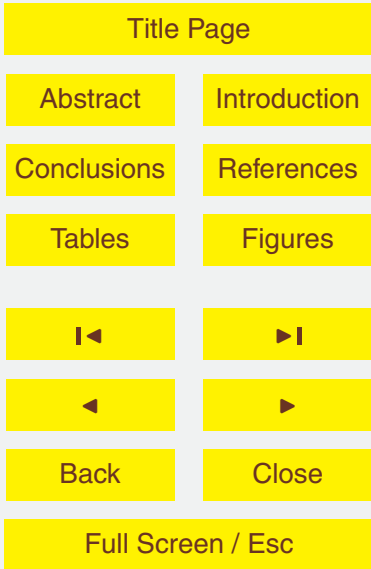

Printer-friendly Version

Interactive Discussion 
Xie, T., Kang, C. L., and Ma, W. Y.: Thermal infrared brightness temperature anomalies associated with the Yushu (China) $M_{s}=7.1$ earthquake on 14 April 2010, Nat. Hazards Earth Syst. Sci., 13, 1105-1111, doi:10.5194/nhess-13-1105-2013, 2013.

Zhou, R. J., Wen, X. Z., Chai, C. X., and Ma, S. H.: Recent earthquakes and assessment of seismic tendency on the Ganzi-Yushu Fault Zone, Seismology and Geology, 19, 115-124, 1997.

\section{NHESSD}

2, 4439-4462, 2014

\section{Study on}

multi-parameters of thermal infrared

remote sensing

anomalies

$X$. Lu et al.

\section{Title Page}

\begin{tabular}{c|c} 
Abstract & Introduction \\
\hline Conclusions & References \\
\hline Tables & Figures \\
\hline
\end{tabular}

14

4

Back

\section{Full Screen / Esc}

Printer-friendly Version 
Table 1. The earthquake magnitude statistics since 1990.

\begin{tabular}{rr}
\hline $\begin{array}{r}\text { Earthquake } \\
\text { magnitude } \\
\text { range }\left(M_{\mathrm{s}}\right)\end{array}$ & $\begin{array}{r}\text { Earthquake } \\
\text { number }\end{array}$ \\
\hline $7.0-7.9$ & 1 \\
$6.0-6.9$ & 3 \\
$5.0-5.9$ & 32 \\
\hline Total & 36 \\
\hline
\end{tabular}

NHESSD

2, 4439-4462, 2014

Study on multi-parameters of thermal infrared remote sensing anomalies

X. Lu et al.

Title Page

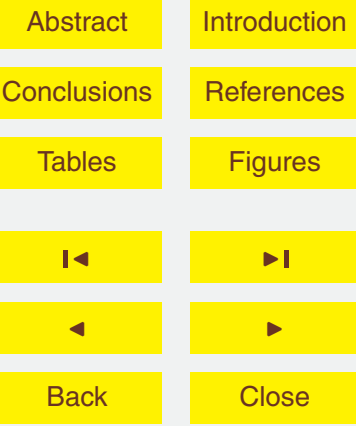

Full Screen / Esc

Printer-friendly Version

Interactive Discussion 
Table 2. Anomalies situation of various observation methods.

\begin{tabular}{|c|c|c|c|}
\hline Name & $\begin{array}{l}\text { The starting time } \\
\text { of anomaly }\end{array}$ & $\begin{array}{l}\text { The anomalous } \\
\text { duration time (Day) }\end{array}$ & Anomaly range \\
\hline $\begin{array}{l}\text { WT } \\
\text { (Well temperature) }\end{array}$ & 20 January & 90 & $\begin{array}{l}\text { Underground } \\
100 \mathrm{~m}\end{array}$ \\
\hline OLR & 15 March & 17 & $\begin{array}{l}\text { The south of the } \\
\text { epicenter }\end{array}$ \\
\hline TBB & 29 March & 17 & $\begin{array}{l}\text { The south of the } \\
\text { epicenter }\end{array}$ \\
\hline LST & 10 April & 16 & $\begin{array}{l}\text { The southwest of } \\
\text { the epicenter }\end{array}$ \\
\hline NCEP & 12 April & 2 & $\begin{array}{l}\text { The southwest of } \\
\text { the epicenter }\end{array}$ \\
\hline
\end{tabular}

NHESSD

2, 4439-4462, 2014

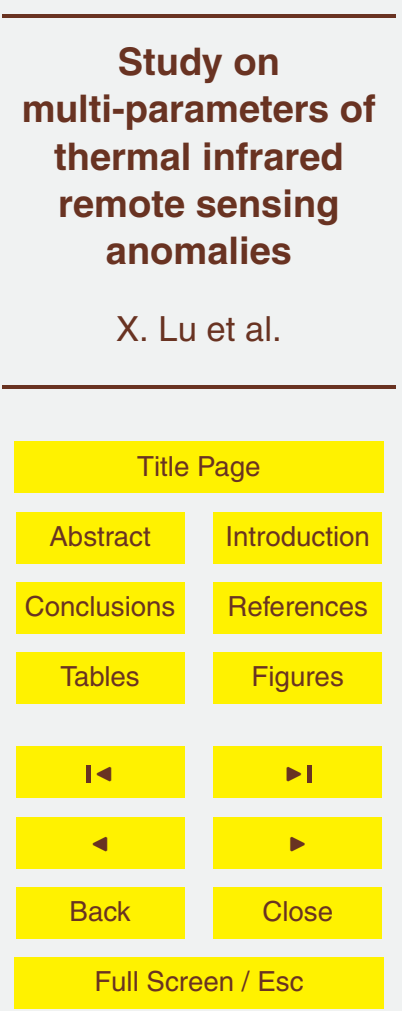

Printer-friendly Version

Interactive Discussion 


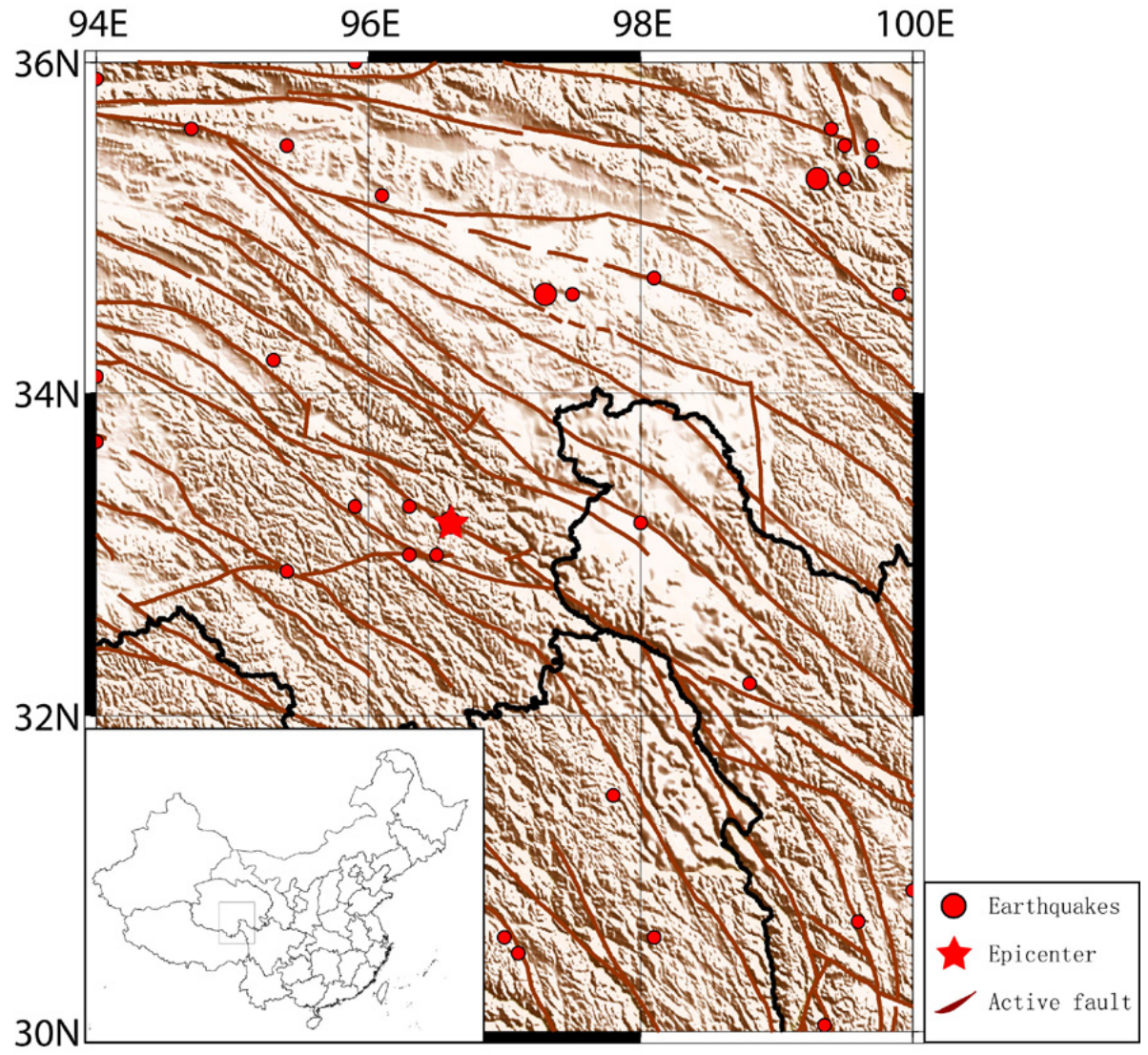

\section{NHESSD}

2, 4439-4462, 2014

\section{Study on}

multi-parameters of thermal infrared remote sensing anomalies

X. Lu et al.

\section{Title Page}

\begin{tabular}{|c|c|}
\hline Abstract & Introduction \\
\hline Conclusions & References \\
\hline Tables & Figures \\
\hline
\end{tabular}

\begin{tabular}{|c|c|}
\hline 14 & $\bullet \mathbf{1}$ \\
\hline 4 & $\bullet$ \\
\hline Back & Close \\
\hline
\end{tabular}

Full Screen / Esc

Figure 1. Tectonic map of Yushu earthquake Circles represent the $M_{\mathrm{s}} \geq 5.0$ magnitude earthquakes in the study area.

Printer-friendly Version

Interactive Discussion 

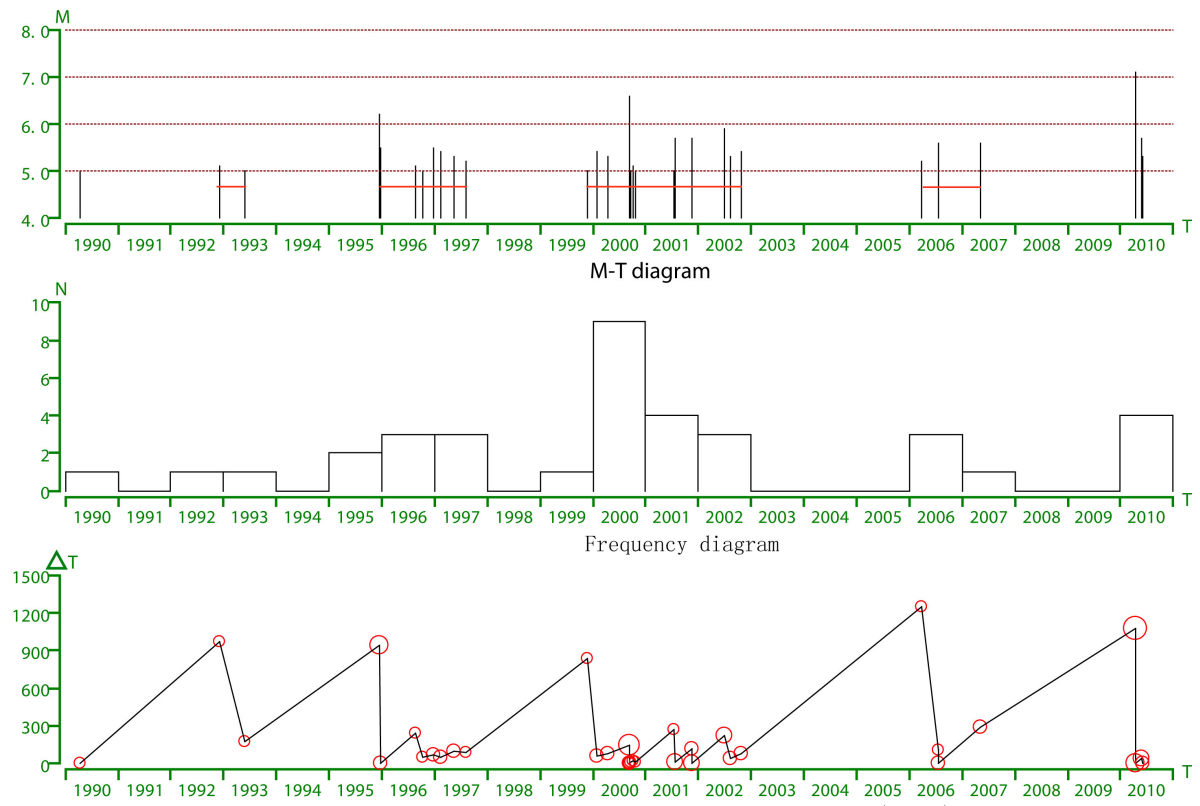

The time interval of earthquakes $(\triangle \mathrm{T}-\mathrm{T})$ diagram

Figure 2. $M-T$, frequency and the time interval of earthquakes $(\Delta T-T)$ diagrams of $M_{\mathrm{s}} \geq 5.0$ magnitude earthquakes in the research area.

\section{NHESSD}

2, 4439-4462, 2014

\section{Study on} multi-parameters of thermal infrared remote sensing anomalies

X. Lu et al.

Title Page

\begin{tabular}{c|c|}
\hline Abstract & Introduction \\
\hline Conclusions & References \\
\hline Tables & Figures \\
\hline 14 & \\
\hline 4 & - \\
\hline Back & Close \\
\hline
\end{tabular}

Full Screen / Esc

Printer-friendly Version

Interactive Discussion 

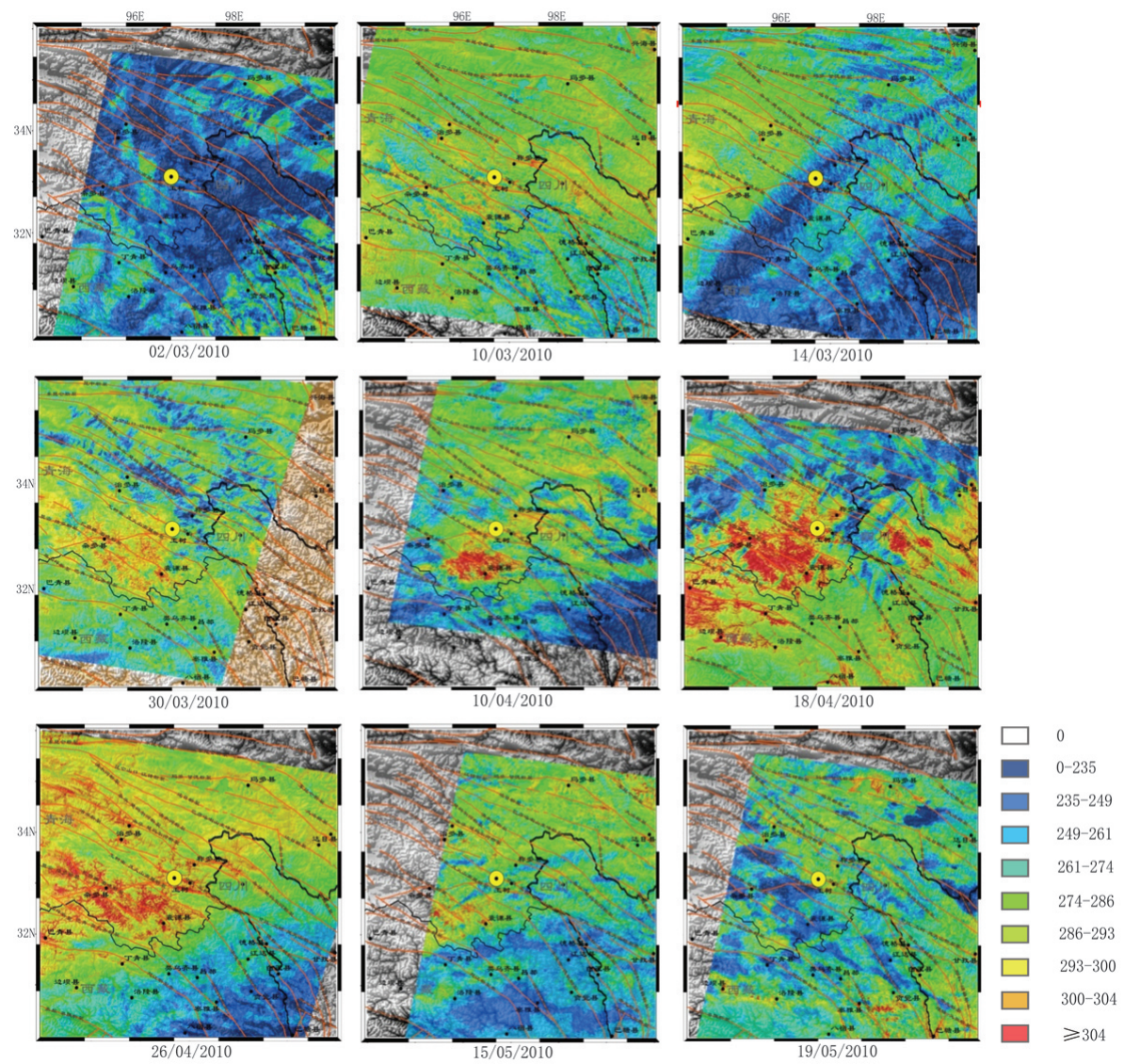

Figure 3. The LST anomaly evolution figure of Yushu earthquake in 2010.

NHESSD

2, 4439-4462, 2014

\section{Study on multi-parameters of thermal infrared remote sensing anomalies}

$X$. Lu et al.

\section{Title Page}

\begin{tabular}{|c|c|}
\hline Abstract & Introduction \\
\hline Conclusions & References \\
\hline Tables & Figures \\
\hline
\end{tabular}

\begin{tabular}{|c|c|}
\hline 14 & $\Delta$ \\
\hline 4 & $\triangleright$ \\
\hline Back & Close \\
\hline
\end{tabular}

Full Screen / Esc

Printer-friendly Version

Interactive Discussion 

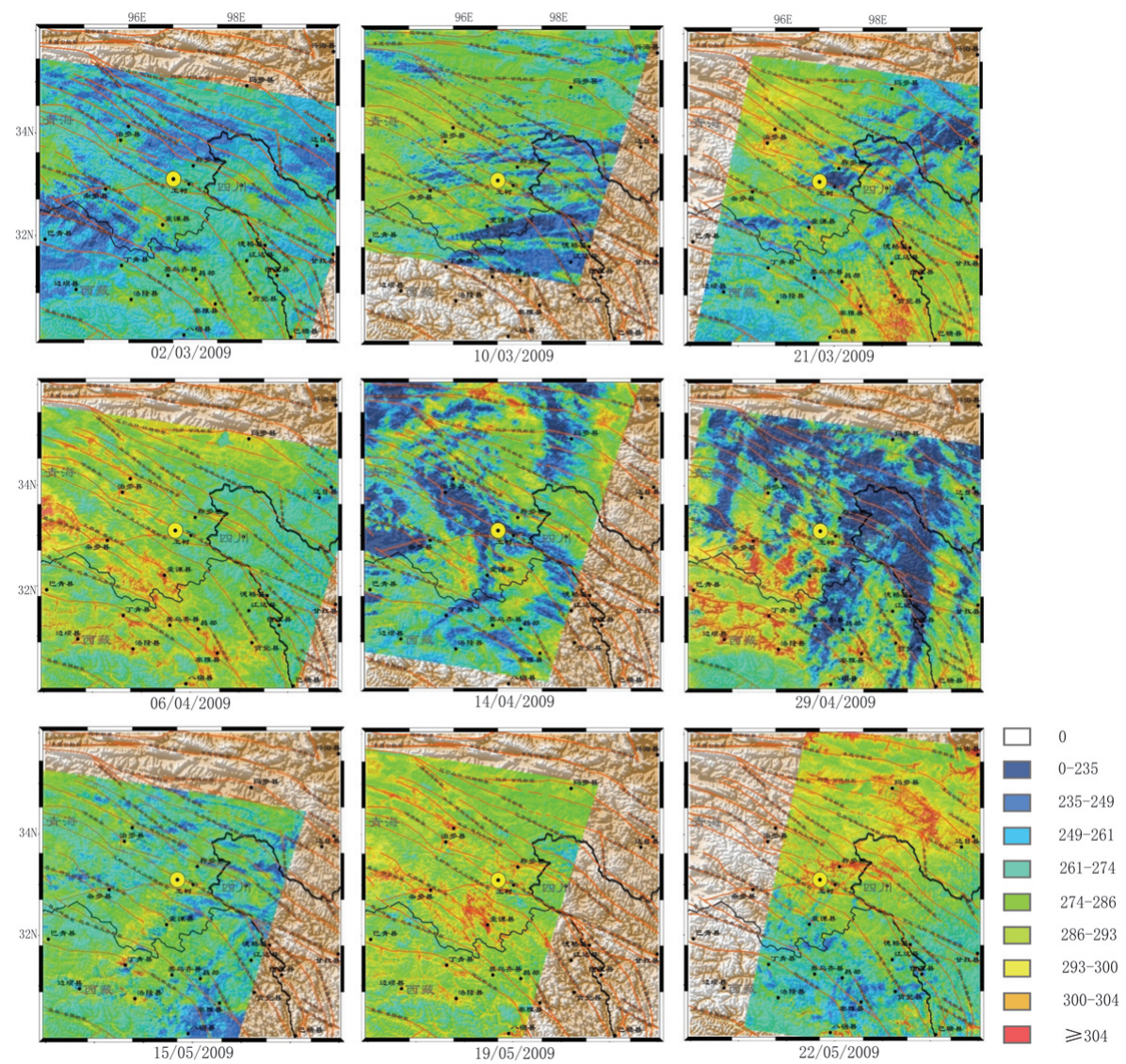

Figure 4. The LST evolution figure in 2009.

\section{NHESSD}

2, 4439-4462, 2014

\section{Study on multi-parameters of thermal infrared remote sensing anomalies}

X. Lu et al.

\section{Title Page}

\begin{tabular}{|c|c|}
\hline Abstract & Introduction \\
\hline Conclusions & References \\
\hline Tables & Figures \\
\hline
\end{tabular}

\begin{tabular}{|c|c|}
\hline 14 & $\rightarrow 1$ \\
\hline 4 & $\bullet$ \\
\hline Back & Close \\
\hline
\end{tabular}

Full Screen / Esc

Printer-friendly Version

Interactive Discussion 


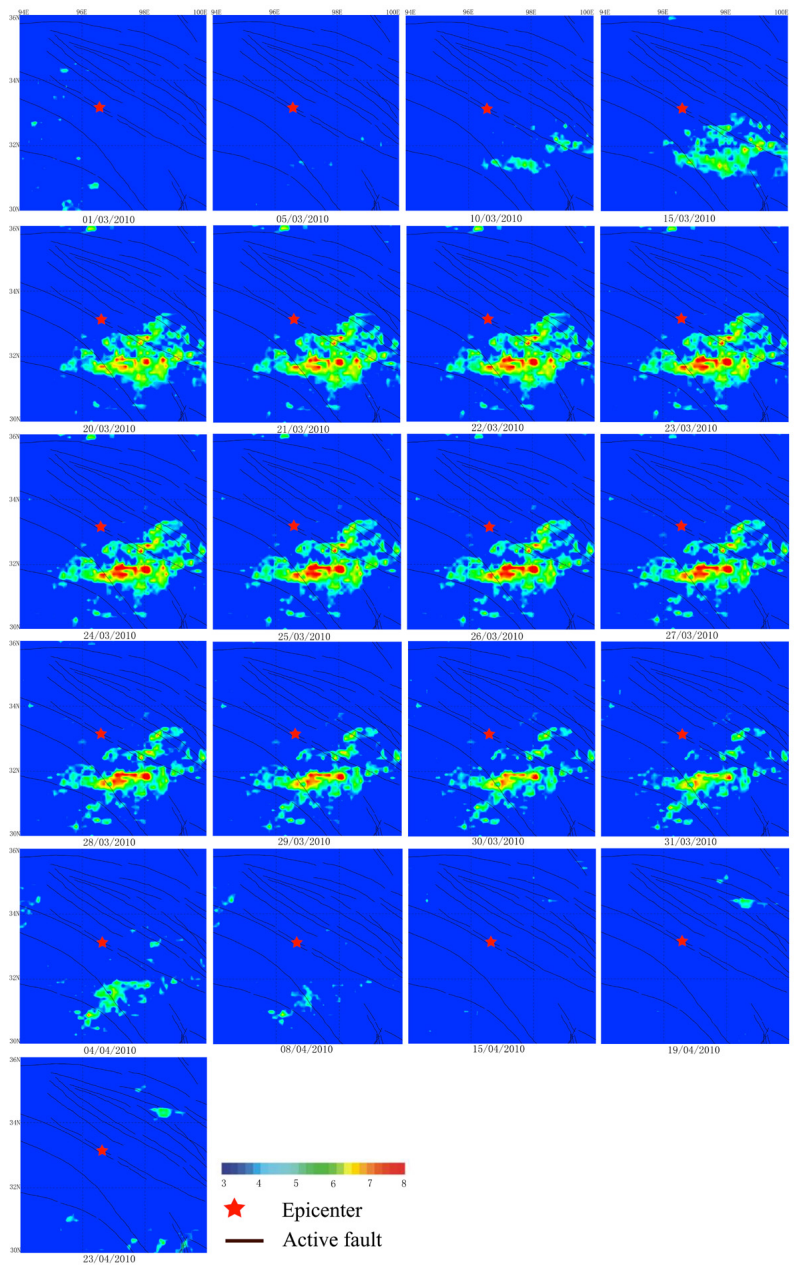

\section{NHESSD}

2, 4439-4462, 2014

Study on multi-parameters of thermal infrared remote sensing anomalies

X. Lu et al.

Title Page

Abstract Introduction

Conclusions References

Tables

Figures

14 $\rightarrow$

4

Back

Close

Full Screen / Esc

Printer-friendly Version

Interactive Discussion

Figure 5. The OLR anomaly evolution figure of Yushu earthquake in 2010. 


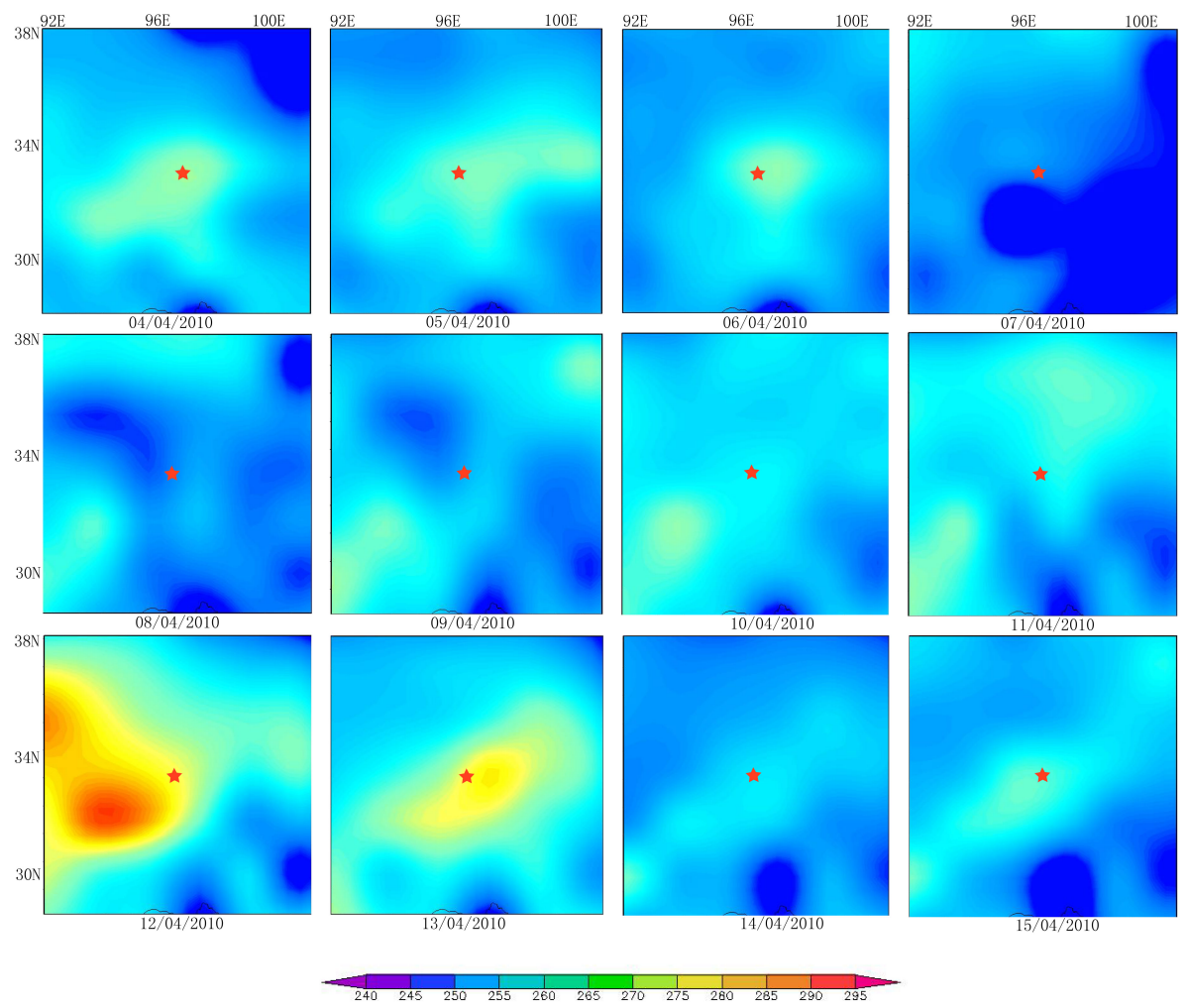

Figure 6. The NCEP anomaly evolution figure of Yushu earthquake in 2010.

\section{NHESSD}

2, 4439-4462, 2014

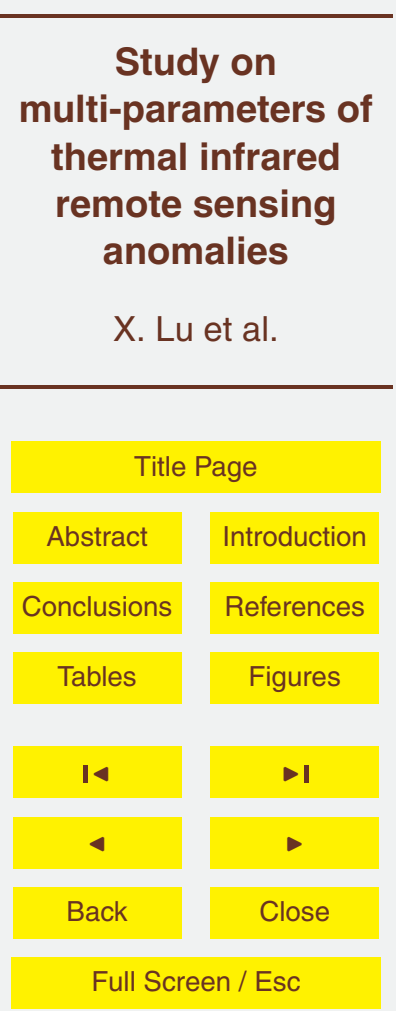

Printer-friendly Version

Interactive Discussion 


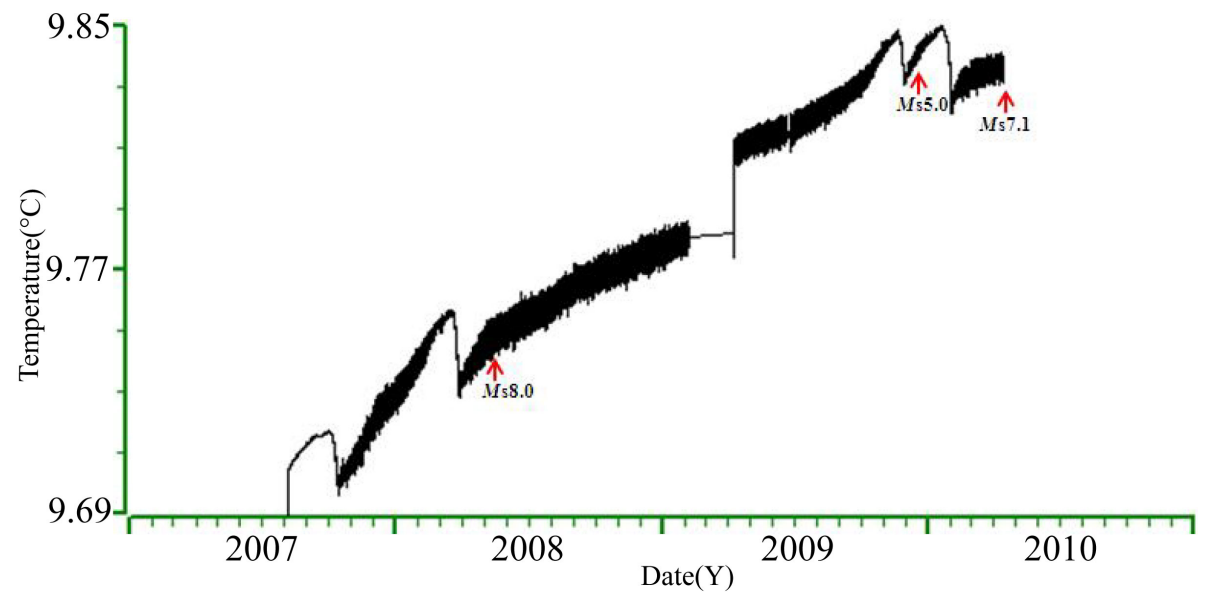

Figure 7. The water temperature data curve of Yushu well.

\section{NHESSD}

2, 4439-4462, 2014

Study on

multi-parameters of thermal infrared

remote sensing anomalies

$X$. Lu et al.

Title Page

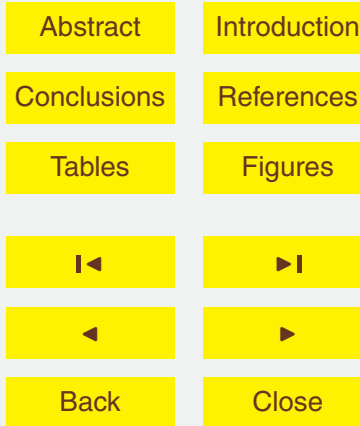

Full Screen / Esc

Printer-friendly Version

Interactive Discussion 